\title{
Growth of 48 built environment bacterial isolates on board the International Space Station (ISS)
}

David A Coil, Russell Y Neches, Jenna M Lang, Wendy E Brown, Mark Severance, Darlene Cavalier, Jonathan A Eisen

Background: While significant attention has been paid to the potential risk of pathogenic microbes aboard crewed spacecraft, the non-pathogenic microbes in these habitats have received less consideration. Preliminary work has demonstrated that the interior of the International Space Station (ISS) has a microbial community resembling those of built environments on earth. Here we report results of sending 48 bacterial strains, collected from built environments on earth, for a growth experiment on the ISS. This project was a component of Project MERCCURI (Microbial Ecology Research Combining Citizen and University Researchers on ISS). Results: Of the 48 strains sent to the ISS, 45 of them showed similar growth in space and on earth using a relative growth measurement adapted for microgravity. The vast majority of species tested in this experiment have also been found in culture-independent surveys of the ISS. Only one bacterial strain showed significantly different growth in space. Bacillus safensis JPL-MERTA-8-2 grew 60\% better in space than on earth. Conclusions: The majority of bacteria tested were not affected by conditions aboard the ISS in this experiment (e.g., microgravity, cosmic radiation). Further work on Bacillus safensis could lead to interesting insights on why this strain grew so much better in space. 
1

3

4 David A Coil ${ }^{1}$, Russell Y Neches ${ }^{1}$, Jenna M Lang ${ }^{1}$, Wendy Brown ${ }^{1,2}$ Mark Severance ${ }^{2,3}$, Darlene 5 Cavalier $^{2,3}$, Jonathan A. Eisen ${ }^{1,4}$

6

7

$8{ }^{2}$ ScienceCheerleader.com

$9{ }^{3}$ SciStarter.org

${ }^{4}$ Evolution and Ecology, Medical Microbiology and Immunology, University of California, Davis, Davis, CA, USA

Corresponding Authors:

David A Coil

451 Health Sciences Drive, Davis, CA, 95618, USA

Email address: coil.david@gmail.com

Jonathan A Eisen

451 Health Sciences Drive, Davis, CA, 95618, USA

Email address: jaeisen@ucdavis.edu 
31

32

33

34

\section{Abstract}

Background: While significant attention has been paid to the potential risk of pathogenic microbes aboard crewed spacecraft, the non-pathogenic microbes in these habitats have received less consideration. Preliminary work has demonstrated that the interior of the International Space Station (ISS) has a microbial community resembling those of built environments on earth. Here we report results of sending 48 bacterial strains, collected from built environments on earth, for a growth experiment on the ISS. This project was a component of Project MERCCURI (Microbial Ecology Research Combining Citizen and University Researchers on ISS).

Results: Of the 48 strains sent to the ISS, 45 of them showed similar growth in space and on earth using a relative growth measurement adapted for microgravity. The vast majority of species tested in this experiment have also been found in culture-independent surveys of the ISS. Only one bacterial strain showed significantly different growth in space. Bacillus safensis JPLMERTA-8-2 grew $60 \%$ better in space than on earth.

Conclusions: The majority of bacteria tested were not affected by conditions aboard the ISS in this experiment (e.g., microgravity, cosmic radiation). Further work on Bacillus safensis could lead to interesting insights on why this strain grew so much better in space.

\section{Introduction}

From 2012-2014, we conducted a nationwide citizen science project, Project MERCCURI http://spacemicrobes.org/, aimed at raising public awareness of microbiology and research on board the International Space Station (ISS). Project MERCCURI (Microbial Ecology Research

51 Combining Citizen and University Researchers on the ISS) was a collaborative effort involving 5 the "microbiology of the Built Environment network" (microBEnet) group, Science Cheerleader, 
53 NanoRacks, Space Florida, and SciStarter. One of the goals of Project MERCCURI was to

54 examine how a number of non-pathogenic bacteria associated with the built environment would

55 grow on board the ISS compared to on earth.

56 Most previous work growing bacteria in space has focused on species known to contain

57 pathogenic strains (e.g. Escherichia coli [Error! Reference source not found.] [Error!

\section{Reference source not found.] and Pseudomonas aeruginosa [Error! Reference source not}

found.] [Error! Reference source not found.]), and much less attention has been paid to the non-pathogenic microbes that surround us. An understandable bias towards pathogens and pathogenic pathways is highlighted by work on topics such as biofilm formation ([Error! Reference source not found.], [Error! Reference source not found.]), antibiotic resistance/production ([Error! Reference source not found.], [Error! Reference source not found.], [Error! Reference source not found.] reviewed in [Error! Reference source not found.]), and virulence ([Error! Reference source not found.], [Error! Reference source not found.]).
Although concern about pathogens in spacecraft is certainly warranted, it should be emphasized that the ability of a pathogen to survive outside a host and the ability to infect a host are both, at least in part, dependent on the existing community of non-pathogenic microbes in those locations. For example, the infectivity of some pathogens has been shown to be very dependent on the host microbiome (e.g. [Error! Reference source not found.], [Error! Reference source not found.], [Error! Reference source not found.] [Error! Reference source not found.]). Therefore, it is important to understand the entire microbial ecosystem of spacecraft. Indeed, in recent years, several culture-independent studies have examined the microbiome of the ISS ([Error! Reference source not found.], [Error! Reference source not 
found.], [Error! Reference source not found.]), including another part of Project MERCCURI [Error! Reference source not found.]. These studies have shown, not surprisingly, that the microbiome of the ISS bears a strong resemblance to the microbiome of human-associated built environments on earth. Therefore, it is of interest to see how microbes from human-associated environments behave in space.

For this study, samples from human-associated surfaces (e.g. toilets, doorknobs, railings, floors, etc.) were collected at a variety of locations around the United States, usually in collaboration with the public. A wide variety of bacteria were cultured from these samples, and 48 non-pathogenic strains were selected for a growth assay comparing growth in microgravity on the ISS and on earth.

\section{Materials and Methods}

\section{Sample collection}

Samples were collected from built environment surfaces throughout the United States on cotton swabs (Puritan 25-806 2PC) and mailed (usually overnight) to the University of California Davis where they were transferred to lysogeny broth (LB) plates. Colonies were chosen for further examination based on maximizing morphological variation. Each chosen colony was double-dilution streaked (two rounds of streak plates) and then the identity determined by direct PCR and Sanger sequencing using the 27F (5'-AGAGTTTGATCMTGGCTCAG-3') and 1391R (5'-GACGGGCGGTGTGTRCA-3') primers (see [Error! Reference source not found.] for details). Sanger sequences were trimmed and aligned using Geneious [Error! Reference source not found.]. The resulting consensus sequence was identified through a combination of BLAST [Error! Reference source not found.] and building phylogenetic trees using the Ribosomal 
98

99

100

101

102

103

104

105

106

107

108

109

110

111

112

113

114

115

116

117

118

119

120

Database Project (RDP) website [Error! Reference source not found.]. The 48 candidates for spaceflight were chosen on the basis of biosafety level (BSL-1 only), taxonomic variety, and human interest. In the absence of international standards, the biosafety level of each organism was determined by searching the American Biological Safety Association (ABSA) risk group database, the American Tissue Culture Collection (ATCC), the Deutsche Sammlung von Mikroorganismen und Zellkulturen (DSMZ), and other public databases. An organism was removed from consideration if it was listed as BSL-2 or higher in any country or collection in the world. Human interest was an arbitrary set of criteria such as unusual physiology, catchy name, or a memorable original isolation source.

\section{Growth Experiment}

A set of bacterial plates were created for each aspect of the study: growth in microgravity on the ISS (space plates), or growth on earth (ground plates). The plates were created using clear agar to facilitate optical density (OD) measurements. $1.5 \mathrm{~g}$ of Gelzan CM agar (Sigma-Aldrich) was added to 1 liter of lysogeny broth (LB). Each well of a flat-bottomed 96-well plate (Costar) was plated with $200 \mu 1$ of agar. The plates were flamed to remove bubbles and incubated for 48 72 hours at room temperature $\left(\sim 20^{\circ} \mathrm{C}\right)$ to ensure sterility before adding bacteria. Fresh overnights of each bacterial isolate were diluted to .01 OD600 and made into 8\% glycerol stocks. For plating, $10 \mu \mathrm{l}$ of each thawed stock dilution was added to 2 wells per 96 well plate. 6 replicate plates were made. The bacteria were placed into different locations on each plate in order to account for drying at the edges or any other positional effects on the plates. The plates were then sealed with adhesive polypropylene film (VWR \#60941-072), into which a grid of micron-diameter holes were cut with a laser to allow for airflow. The ground plates were stored at $-80^{\circ} \mathrm{C}$ at UC Davis, and the space plates were mailed on dry ice to the National Aeronautics 
121 and Space Administration (NASA) Johnson Space Center in Houston, TX before transfer (at -80

$\left.122{ }^{\circ} \mathrm{C}\right)$ to Cape Canaveral, FL for launch.

123 This payload was flown on the CRS-3 launch of the Space Exploration Technologies

124 (SpaceX) Dragon spacecraft, on a Falcon 9 v1.1 rocket which successfully launched April 18, 125 2014. After six days, the space plates were removed from the MELFI (Minus Eighty Lab Freezer

126 For ISS) and partially thawed. However, technical problems arose and the space plates were

127 placed back into the MELFI until December 8, 2014. At that time, all three plates were thawed

128 and the OD600 of each well (3x3 grid) was measured at time 0 (60 minutes after removal from

129 the freezer) and then every 24 hours for 4 days. Measurements were performed in a Molecular

130 Devices SpectraMax M5e plate reader which was modified for integration onto the ISS. On these

131 same days, equivalent measurements of the ground plates were taken in a Molecular Devices

132 SpectraMax M5e plate reader at UC Davis. The exception to this was the initial partial thawing,

133 which was not replicated with the ground plates since the amount of thaw was not reported by

134 the astronauts. After the experiment, the ground plates were placed back at $-80{ }^{\circ} \mathrm{C}$ and the space

135 plates were placed back into the MELFI. In February 2015, the space plates were transferred to a

$136-95^{\circ} \mathrm{C}$ freezer on board a Dragon spacecraft. The vehicle splashed down in the Pacific Ocean on

137 Feb 10, 2015. The space plates were then mailed to UC Davis on dry ice and were transferred to

$138-80{ }^{\circ} \mathrm{C}$ when received.

139 Once the plates arrived, we thawed all six plates and performed a high-density measurement 140 in a Tecan M200 plate reader. OD600 readings were taken in a 5x5 grid covering the entire well, 141 these 25 measurements were then averaged within each well.

142 Analysis 
For each sample, the averages of the six space replicates and six ground replicates were

144

145

146

147

148

149

150

151

152

153

154

155

156

157

158

159

160

161

162

163

164

compared using a Student's t-test. To correct for multiple hypothesis testing, the p-values were adjusted using the False Discovery Rate (FDR) method [Error! Reference source not found.]. All raw data, analyses and scripts can be found at https://zenodo.org/record/44661.

\section{Confirmation}

In order to confirm that the observed results were not due to contamination of the wells, each of the 12 replicates (six space, six ground) for the three bacteria showing statistically different growth between the ISS and earth were cultured after the experiment. Bacteria were struck from the wells onto LB-agar plates, then single colonies were grown into overnight cultures. DNA was extracted using a Wizard Genomic DNA Purification kit (Promega) from each of the 36 cultures (3 bacteria X 12 replicates) and the identity was confirmed by BLAST of the Sanger sequenced PCR product using the $27 \mathrm{~F}$ and $1391 \mathrm{R}$ primers as described above.

\section{Comparison to ISS swab data}

The bacterial community on the ISS was recently surveyed by PCR amplification and sequencing of 16S rRNA genes from swabs [Error! Reference source not found.]. We compared the $16 \mathrm{~S}$ sequence of each of our bacterial isolates to the "representative sequence" from each operational taxonomic unit (OTU) generated from the survey data. A BLASTN search was performed locally and a match was considered to be present in the data when there was $97 \%$ identity over at least $250 \mathrm{bp}$ of the rRNA sequence (the amplified fragment is $253 \mathrm{bp}$ ).

\section{Results and Discussion}

Growth experiments are typically undertaken in liquid media, in part because measuring the optical density of a liquid culture is straightforward. However, liquid cultures present a number 
165 of problems in microgravity. Most organisms that passed our screening did not grow well under 166 anaerobic conditions, and thus required some sort of gas exchange with the surrounding air. On

167 the ground, aerobic conditions are easily created by incubating in open or loosely capped vessels.

168 This is impractical and unsafe in microgravity; there is no "safe" orientation in which the liquid

169 will remain in place. We explored several unsuccessful approaches to this problem. For example,

170 we found that gas-permeable plate seals leak when inverted, and their adhesion failed completely

171 after freezing. We also fabricated custom plates with seals made from hydrophobic

172 polydimethylsiloxane (PDMS) with micron-diameter vent holes, but these also leaked when

173 inverted.

174 We eventually concluded that the design requirements were mutually exclusive; either we 175 could achieve containment for liquid cultures at the expense of aerobic conditions, or we could 176 achieve aerobic conditions at the expense of liquid culture containment. We chose the latter, so 177 our plates were prepared with solid media. Solid media is not traditionally used for OD 178 measurements, and so our results need to be interpreted differently from OD in liquid culture.

179 Using clear agar to maximize transparency, we programmed the plate reader to take OD 180 measurements at nine different locations in each well, each of which was measured twenty five 181 times per observation. The plates were inoculated in a manner intended to create many small 182 colonies (see Materials and Methods). As these colonies grow, their edges intersect with reading 183 points, and the OD for that point increases in a stepwise fashion. As the colony thickens, the OD 184 gradually increases. OD in liquid media is thought to correspond to scattering of light by 185 individual cells, whereas our measurements correspond to the number, diameter, and thickness of 186 the colonies. The intervals elapsed between occultations of the reading points decrease 187 exponentially, and so the average OD across each well behaves very similarly to traditional 
188 observations of log-phase growth in liquid media. However, in the absence of correlation with

189 the gold standard of dilution plate counts, this should be considered as a relative measure of

190 growth. This was validated by repeated growth experiments on earth, showing normal growth

191 kinetics of colonies grown with this method, an sample dataset is shown in Supplementary

192 Figure 1. To our knowledge this is the first use of solid media to measure bacterial growth

193 kinetics in this manner. The data from the different plate readers (Tecan and Molecular

194 Dynamics) was compared at 96 hours by plotting the OD600 values against each other. While

195 the concordance was not perfect, there was a strong relationship between the two machines

196 which provided validation of the data from both Molecular Dynamics machines (ground and

197 space).

198

By this measure, the vast majority of the bacteria (45/48) behaved very similarly in space and

on earth (Table 1). Only three bacteria showed a significant difference in the two conditions;

200

Bacillus safensis, Bacillus methylotrophicus, and Microbacterium oleivorans. As part of double

201

checking these results, we performed Sanger sequencing of rRNA genes from the wells

202

corresponding to each of these species of the space plates and ground plates. A few wells

203

produced mixed Sanger sequence, suggesting the presence of more than one organism in the

well. In addition, a couple of wells gave a clear identification of a contaminating organism. We

therefore inferred that there had been some contamination of the B. methylotrophicus and $M$.

oleivorans wells. Since the remaining 45 organisms were not tested for contamination, it is

207 possible that some of those represent false negatives. The B. safensis wells were all clear of any

208 signs of contamination.

209 This Bacillus safensis strain was collected at the Jet Propulsion Laboratory (JPL-NASA) on a

210 Mars Exploration Rover before launch in 2004. As part of standard Planetary Protection 
211 protocols, all surface-bound spacecraft are sampled during the assembly process and those

212 strains are then saved for further analysis. We obtained this strain as part of a collection of JPL-

213 NASA strains to send to the ISS (Table 1). In this experiment, Bacillus safensis grew to a final

214 density of $\sim 60 \%$ higher in space than on the ground, with very little variation between replicates

215 (Figure 1). The genome sequence of this strain, Bacillus safensis JPL-MERTA-8-2 has just been

216 published [Error! Reference source not found.] and may contain clues as to why this strain

217 behaved so differently in space.

218 It is perhaps no surprise that most built environment-associated bacteria behave very similarly

219 on the ISS as on earth. After all, the ISS is a home and office of sorts, with environmental

220 conditions very similar to a building on earth with the exception of gravity. The ISS is

221 maintained at around $22{ }^{\circ} \mathrm{C}$ with a relative humidity of around $60 \%$ and pressure and oxygen

222 concentrations very close to those at sea level on earth. Additionally, this experiment did not

223 provide enough time to study the long-term adaptation of bacteria to the environment on board

224 the ISS.

225 A related project from our lab has examined the microbial community already present on the

226 ISS [Error! Reference source not found.]. Given that the ISS appears to harbor similar

227 microbes to built environments on earth, we also asked if there were close relatives to our 48

228 bacteria already present on the ISS. The vast majority (39/48) of our bacterial species were found

229 in the existing microbial community data which is not surprising given the built environment

230 origins of the isolates. This suggests that our data showing these species growing with similar

231 kinetics on space and on earth is potentially relevant to the biology of the microbial communities

232 already present on the ISS.

233 Acknowledgements 
257

258

259

260

261

262

263

264

265

266

267

268

The authors would like to thank the many people who contributed to Project MERCCURI and to the processing of these cultures including Pop Warner, Science Cheerleaders, Nanoracks LLC, Space Florida, SciStarter, Jennifer Flanagan, Ruth Lee, Hannah Holland-Moritz, Alex Alexiev, Madison Dunitz, and Holly Bik. In particular, thanks to Carl Carruthers at Nanoracks LLC who shepherded the payload through all challenges. This article was written using the Authorea scientific writing platform.

\section{References}

(1) SF Altschul, W Gish, W Miller, EW Myers, and DJ Lipman. Basic local alignment search tool. J Mol Biol, 215:403-10, Oct 1990.

(2) Y Benjamini and Y Hochberg. Controlling the False Discovery Rate: A Practical and Powerful Approach to Multiple Testing. Journal of the Royal Statistical Society. Series B (Methodological), 57(1):289-300, 1995.

(3) MR Benoit, W Li, LS Stodieck, KS Lam, CL Winther, TM Roane, and DM Klaus. Microbial antibiotic production aboard the International Space Station. Appl Microbiol Biotechnol, 70:403-11, Apr 2006.

(4) RB Brown, D Klaus, and P Todd. Effects of space flight, clinorotation, and centrifugation on the substrate utilization efficiency of E. coli. Microgravity Sci Technol, $13: 24-9,2002$.

(5) VA Castro, AN Thrasher, M Healy, CM Ott, and DL Pierson. Microbial characterization during the early habitation of the International Space Station. Microb Ecol, 47:119-26, Feb 2004.

(6) DA Coil, JN Benardini, and JA Eisen. Draft Genome Sequence of Bacillus safensis JPLMERTA-8-2, Isolated from a Mars-Bound Spacecraft. Genome Announc, 3, Nov 2015.

(7) JR Cole, Q Wang, JA Fish, B Chai, DM McGarrell, Y Sun, CT Brown, A Porras-Alfaro, CR Kuske, and JM Tiedje. Ribosomal Database Project: data and tools for high throughput rRNA analysis. Nucleic Acids Res, 42:D633-42, Jan 2014. 
(8) A Crabbé, MJ Schurr, P Monsieurs, L Morici, J Schurr, JW Wilson, CM Ott, G Tsaprailis, DL Pierson, H Stefanyshyn-Piper, and CA Nickerson. Transcriptional and proteomic responses of Pseudomonas aeruginosa PAO1 to spaceflight conditions involve Hfq regulation and reveal a role for oxygen. Appl Environ Microbiol, 77:122130, Feb 2011.

(9) MI Dunitz, JM Lang, G Jospin, AE Darling, JA Eisen, and DA Coil. Swabs to genomes: a comprehensive workflow. PeerJ, 3:e960, 2015.

(10) TG Hammond, L Stodieck, HH Birdsall, JL Becker, P Koenig, JS Hammond, MA Gunter, and PL Allen. Effects of microgravity on the virulence of Listeria monocytogenes, Enterococcus faecalis, Candida albicans, and methicillin-resistant Staphylococcus aureus. Astrobiology, 13:1081-90, Nov 2013.

(11) T Ichinohe, IK Pang, Y Kumamoto, DR Peaper, JH Ho, TS Murray, and A Iwasaki. Microbiota regulates immune defense against respiratory tract influenza A virus infection. Proc Natl Acad Sci US A, 108:5354-9, Mar 2011.

(12) MA Juergensmeyer, EA Juergensmeyer, and JA Guikema. Long-term exposure to spaceflight conditions affects bacterial response to antibiotics. Microgravity Sci Technol, 12:41-7, 1999.

(13) M Kearse, R Moir, A Wilson, S Stones-Havas, M Cheung, S Sturrock, S Buxton, A Cooper, S Markowitz, C Duran, T Thierer, B Ashton, P Meintjes, and A Drummond. Geneious Basic: an integrated and extendable desktop software platform for the organization and analysis of sequence data. Bioinformatics, 28:1647-9, Jun 2012.

(14) SW Kembel, E Jones, J Kline, D Northcutt, J Stenson, AM Womack, BJ Bohannan, GZ Brown, and JL Green. Architectural design influences the diversity and structure of the built environment microbiome. ISME J, 6:1469-79, Aug 2012.

(15) W Kim, FK Tengra, J Shong, N Marchand, HK Chan, Z Young, RC Pangule, M Parra, JS Dordick, JL Plawsky, and CH Collins. Effect of spaceflight on Pseudomonas aeruginosa final cell density is modulated by nutrient and oxygen availability. BMC Microbiol, 13:241, Nov 2013.

(16) W Kim, FK Tengra, Z Young, J Shong, N Marchand, HK Chan, RC Pangule, M Parra, JS Dordick, JL Plawsky, and CH Collins. Spaceflight promotes biofilm formation by Pseudomonas aeruginosa. PLoS One, 8:e62437, 2013.

(17) D Klaus, S Simske, P Todd, and L Stodieck. Investigation of space flight effects on Escherichia coli and a proposed model of underlying physical mechanisms. Microbiology, 143 ( Pt 2):449-55, Feb 1997.

(18) DM Klaus and HN Howard. Antibiotic efficacy and microbial virulence during space flight. Trends Biotechnol, 24:131-6, Mar 2006. 
(19) KS Lam, DR Gustavson, DL Pirnik, E Pack, C Bulanhagui, SW Mamber, S Forenza, LS Stodieck, and DM Klaus. The effect of space flight on the production of actinomycin D by Streptomyces plicatus. J Ind Microbiol Biotechnol, 29:299-302, Dec 2002.

(20) JM Lang, DA Coil, JA Eisen, RY Neches, W Brown, D Cavalier, M Severance, J Marcel, and J Gilbert. A microbial survey of an extreme built environment: the International Space Station (ISS). Submitted.

(21) RJ McLean, JM Cassanto, MB Barnes, and JH Koo. Bacterial biofilm formation under microgravity conditions. FEMS Microbiol Lett, 195:115-9, Feb 2001.

(22) Christine Moissl, Naofumi Hosoya, James Bruckner, Tara Stuecker, Monsi Roman, and Kasthuri Venkateswaran. Molecular microbial community structure of the Regenerative Enclosed Life Support Module Simulator air system. International Journal of Astrobiology, 6(02):131, mar 2007.

(23) CA Nickerson, CM Ott, SJ Mister, BJ Morrow, L Burns-Keliher, and DL Pierson. Microgravity as a novel environmental signal affecting Salmonella enterica serovar Typhimurium virulence. Infect Immun, 68:3147-52, Jun 2000.

(24) AE Reeves, CM Theriot, IL Bergin, GB Huffnagle, PD Schloss, and VB Young. The interplay between microbiome dynamics and pathogen dynamics in a murine model of Clostridium difficile Infection. Gut Microbes, 2:145-58, May 2011.

(25) TJ Schuijt, JM Lankelma, BP Scicluna, Sousa E Melo F de, JJ Roelofs, Boer JD de, AJ Hoogendijk, Beer R de, Vos A de, C Belzer, Vos WM de, der Poll T van, and WJ Wiersinga. The gut microbiota plays a protective role in the host defence against pneumococcal pneumonia. Gut, Oct 2015.

(26) Rensburg JJ van, H Lin, X Gao, E Toh, KR Fortney, S Ellinger, B Zwickl, DM Janowicz, BP Katz, DE Nelson, Q Dong, and SM Spinola. The Human Skin Microbiome Associates with the Outcome of and Is Influenced by Bacterial Infection. MBio, 6:e01315-15, Sep 2015.

(27) K Venkateswaran, P Vaishampayan, J Cisneros, DL Pierson, SO Rogers, and J Perry. International Space Station environmental microbiome - microbial inventories of ISS filter debris. Appl Microbiol Biotechnol, 98:6453-66, 2014. 


\section{1}

Growth (OD600) over time of Bacillus safensis JPL-MERTA-8-2

Growth (OD600) over time of Bacillus safensis JPL-MERTA-8-2 in space (green) and on earth (brown). Values represent the mean of 6 wells, +/- the standard deviation.

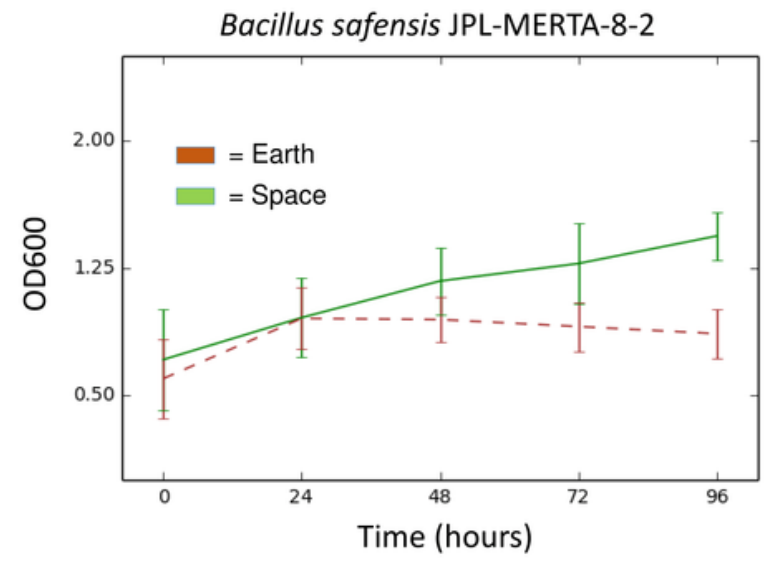




\section{Table $\mathbf{1}$ (on next page)}

Final growth (OD600) of all 48 strains as measured on earth at the end of the experiment with a high-density measurement in a Tecan platereader.

Table 1: Values represent the mean of 6 wells, $+/$ - the standard deviation. Difference between space and earth were determined using a Student's t-test and the $p$-values were adjusted for multiple hypothesis testing by using the False Discovery Rate (FDR). 


\begin{tabular}{|c|c|c|c|c|c|}
\hline Organism & Location & Source & Mean OD (space & Mean OD (ground) & FDR p-value \\
\hline Bacillus safensis & JPL-NASA (CA) & Mars Exploration Rover & $1.44+/-0.09$ & $0.86+/-0.07$ & 0 \\
\hline Bacillus methylotrophicus & Yuri's Night New York (NY) & Doorknob & $1.54+/-0.05$ & $1.69+/-0.09$ & 0 \\
\hline Microbacterium oleivorans & St. Joseph's Prep (PA) & School mascot & $1.61+/-0.3$ & $1.93+/-0.14$ & 0.04 \\
\hline Bacillus atrophaeus & JPL-NASA (CA) & Mars Exploration Rover & $1.69+/-0.05$ & $1.57+/-0.14$ & 0.07 \\
\hline Porphyrobacter mercurialis & Pop Warner: Coronado (CA) & Stadium seat & $0.85+/-0.13$ & $1.03+/-0.2$ & 0.07 \\
\hline Bacillus flexus & NFL: Tennesse Titans (TN) & Stadium field & $1.47+/-0.24$ & $1.72+/-0.1$ & 0.07 \\
\hline Bacillus atrophaeus & Denver Museum of Nature and Science (CO) & Antique microscope & $1.62+/-0.06$ & $1.3+/-0.25$ & 0.14 \\
\hline Bacillus altitudinis & Deerfield Academy (MA) & School field & $1.23+/-0.09$ & $1.22+/-0.15$ & 0.14 \\
\hline Macrococcus brunensis & WHYY Radio (PA) & Keyboard & $1.06+/-0.15$ & $1.29+/-0.11$ & 0.14 \\
\hline Bacillus tequilensis & Today Show (NY) & Candy jar & $1+/-0.21$ & $1.09+/-0.1$ & 0.14 \\
\hline Bacillus amyloliquefaciens & NFL: New England Patriots (MA) & Stadium seat & $1.41+/-0.13$ & $1.53+/-0.12$ & 0.14 \\
\hline Bacillus subtilis & JPL-NASA (CA) & Robotic arm (Insight) & $1.32+/-0.16$ & $1.08+/-0.25$ & 0.16 \\
\hline Micrococcus luteus & NBA: Sacramento Kings (CA) & Sweat mop & $1.01+/-0.08$ & $0.87+/-0.16$ & 0.21 \\
\hline Leucobacter chironomi & Davis (CA) & Toilet & $1.03+/-0.27$ & $1.03+/-0.12$ & 0.21 \\
\hline Kocuria kristinae & NBA: San Antonio Spurs (TX) & Court floor & $1.93+/-0.06$ & $1.85+/-0.16$ & 0.21 \\
\hline Kocuria rhizophila & Yuri's Night Los Angeles (CA) & Camera & $2.01+/-0.14$ & $1.97+/-0.19$ & 0.21 \\
\hline Bacillus stratosphericus & Academy of Natural Science (PA) & Water dish & $1.34+/-0.14$ & $1.1+/-0.13$ & 0.21 \\
\hline Bacillus tequilensis & MBA: Philadelphia Phillies (PA) & Dugout & $1.41+/-0.18$ & $1.03+/-0.15$ & 0.21 \\
\hline Micrococcus luteus & Pop Warner: Lake Brantley (FL) & Football goalpost & $1.71+/-0.03$ & $1.69+/-0.06$ & 0.21 \\
\hline Paenibacillus mucilaginosus & Field Museum (IL) & "Sue" the T-rex & $1.57+/-0.13$ & $1.54+/-0.14$ & 0.21 \\
\hline Exiguobacterium sibiricum & AT\&T Park (CA) & Second base & $1.3+/-0.23$ & $1.38+/-0.14$ & 0.21 \\
\hline Exiguobacterium indicum & NFL: Team from Washington D.C. & Stadium field & $1.26+/-0.16$ & $1.17+/-0.23$ & 0.21 \\
\hline Curtobacterium pusillum & UC Davis (CA) & Stadium gate & $1.28+/-0.3$ & $1.49+/-0.14$ & 0.21 \\
\hline Kocuria marina & Yuri's Night North Carolina (NC) & Water Fountain & $1.77+/-0.1$ & $1.73+/-0.08$ & 0.26 \\
\hline Bacillus megaterium & The Liberty Bell (PA) & The Liberty Bell & $1.38+/-0.24$ & $1.46+/-0.15$ & 0.34 \\
\hline Bacillus lichenformis & NBA: Philadelphia 76ers (PA) & Practice court & $1.18+/-0.13$ & $1.07+/-0.14$ & 0.34 \\
\hline Bacillus megaterium & JPL-NASA (CA) & Mars Curiosity Rover & $1.6+/-0.14$ & $1.55+/-0.16$ & 0.38 \\
\hline Bacillus subtilus & NBA: Orlando Magic (FL) & Game ball & $1.35+/-0.08$ & $1.17+/-0.19$ & 0.38 \\
\hline Arthrobacter nitroguajacolicus & Chapman Hill Elementary (OR) & Stadium field & $1.67+/-0.12$ & $1.76+/-0.25$ & 0.44 \\
\hline Bacillus aryabhattai & NFL: Oakland Raiders (CA) & Practice field & $1.62+/-0.3$ & $1.64+/-0.13$ & 0.44 \\
\hline Microbacteria arborescens & JPL-NASA (CA) & Viking Mars Orbiter & $1.69+/-0.26$ & $1.59+/-0.47$ & 0.49 \\
\hline Bacillus pumilus & JPL-NASA (CA) & Mars Exploration Rover & $0.97+/-0.25$ & $1.26+/-0.25$ & 0.49 \\
\hline Paenibacillus elgii & JPL-NASA (CA) & Mars Exploration Rover & $1.39+/-0.3$ & $0.84+/-0.14$ & 0.49 \\
\hline Kocuria rosea & JPL-NASA (CA) & Mars Exploration Rover & $1.61+/-0.26$ & $1.53+/-0.18$ & 0.49 \\
\hline Bacillus aryabhattai & Pop Warner: Broncos (FL) & Stadium field & $1.65+/-0.28$ & $1.54+/-0.05$ & 0.49 \\
\hline Micrococcus yunnanensis & Discover Magazine (WI) & Dictionary & $1.68+/-0.41$ & $1.75+/-0.23$ & 0.49 \\
\hline Bacillus amyloliquefaciens & Franklin Institute (PA) & Statue & $1.4+/-0.09$ & $1.38+/-0.14$ & 0.6 \\
\hline Bacillus megaterium & Chemical Heritage Foundation (PA) & Antique pressure vessel & $1.57+/-0.43$ & $1.56+/-0.14$ & 0.61 \\
\hline Exiguobacterium acetylicum & NFL: San Franciso 49ers (CA) & Stadium field & $1.57+/-0.18$ & $1.53+/-0.21$ & 0.61 \\
\hline Bacillus horikoshii & Parkway Middle School (FL) & Banister & $1.53+/-0.34$ & $1.67+/-0.09$ & 0.61 \\
\hline Macrococcus equipercicus & Catholic Montessori School (OH) & Floor & $0.99+/-0.19$ & $0.94+/-0.2$ & 0.64 \\
\hline Streptomyces kanamyceticus & KARE11 Morning News (MN) & Set kitchen & $1.11+/-0.2$ & $0.92+/-0.16$ & 0.66 \\
\hline Pantoea eucrina & Smithsonian Air and Space Museum (D.C.) & Mercury Orbiter & $1.57+/-0.31$ & $1.57+/-0.09$ & 0.76 \\
\hline Bacillus horikoshii & Pop Warner: Saints (NJ) & Stadium field & $1.64+/-0.2$ & $1.58+/-0.07$ & 0.79 \\
\hline Curtobacterium herbarum & Georgia Tech (GA) & Stadium seat & $1.42+/-0.19$ & $1.5+/-0.13$ & 0.79 \\
\hline Bacillus pumilus & Pop Warner: Chittanoga (NY) & Porta-Potty handle & $1.17+/-0.31$ & $1.35+/-0.12$ & 0.82 \\
\hline Micrococcus luteus & Pop Warner: Apopka (FL) & Practice mat & $0.99+/-0.27$ & $0.86+/-0.34$ & 0.82 \\
\hline Bacillus marisflavi & Pop Warner: PeeWee Bengals (NC) & Stadium field & $1.66+/-0.19$ & $1.61+/-0.26$ & 0.82 \\
\hline
\end{tabular}

